\title{
COARCTATION OF THE AORTA WITH PATENT DUCTUS ARTERIOSUS
}

\author{
BY \\ J. GIBSON GRAHAM AND J. D. OLAV KERR \\ Received February 28, 1941
}

While serving in the R.A.M.C. at a military hospital, it has been our good fortune to see a considerable number of patients with congenital heart disease. One of these with coarctation of the aorta presented certain unusual features, notably patency of the ductus arteriosus. In themselves these two defects are not amongst the rarer developmental abnormalities of the cardiovascular system, but their combination in a diagnosis made during life appears to be rare enough to justify detailed consideration.

Evans (1933) stated that coarctation of the aorta was found in approximately one in every 1000 necropsies, while Blackford (1928) estimated the incidence as one in every 1550 necropsies.

Patency of the ductus arteriosus occurred in 262 of Abbott's (1936) series of 1000 cases of congenital cardiac defects; in 40 it was combined with pulmonary atresia or stenosis, in each instance being associated with a septal defect. In the same series of 1000 cases she described 178 examples of coarctation of the aorta, of which 105 belonged to the adult type; 70 were analysed in detail, and in only 6 of these was the ductus arteriosus patent.

\section{DesCription OF THE CASE}

Our patient, aged 25, was the wife of a corporal. There was nothing of note in the family history. Both parents, her sisters, and two brothers were alive and well; her husband was in good health. She herself could remember no previous illness, apart from diphtheria at twelve years, when she was ill for six weeks. As a child she had made no complaint of breathlessness, and took part in all games when at school with enjoyment. Later she was employed as a shop assistant without incident. She was married at nineteen years and was evidently a most active housewife. A year later she became pregnant, and at the seventh month began to suffer for the first time from headache, nausea, and vomiting that was difficult to control. While no œdema was observed, albumin was present in the urine, and on the fifth day of severe symptoms the pregnancy was terminated. It should be noted that there was no history of convulsions. All symptoms disappeared in three days, but she was told she had "kidney trouble" and that another pregnancy would be strongly contra-indicated. This unfavourable prognosis apparently induced 
an element of introspection and doubt as to her own well-being which led the patient to present herself at various hospitals for examination; however, little amiss seems to have been found. In September 1940 she was six weeks in hospital with a diagnosis of pyelitis. At this time there was some dysuria which continued to a lesser extent, but at no time had polyuria been noted.

She came under the care of one of us (J. G. G.) some four months later with a provisional diagnosis of chronic nephritis. She made no specific complaint apart from slight discomfort on micturition and lumbar pain when tired. However, she volunteered that she became breathless on exertion and that her lips occasionally turned blue, her nails becoming blue easily in cold weather. She also stated that her feet were always cold, although there was no history of chilblains or of intermittent claudication.

The patient was of small build and stature (height, 4 feet, 11 inches; weight, 91 pounds), and was somewhat pallid and wax-like in complexion. On admission to hospital there was no cyanosis or clubbing of the fingers, nor was there any evidence of dilated vessels in the thorax; there was, however, marked arterial pulsation at the root of the neck. Neither dyspnœa nor orthopnœa was noted. Physical examination of lungs, abdomen, and nervous system did not show any abnormality.

Cardiovascular System. The pulse rate was 70 per minute, the rhythm being regular; the force was good, but the pressure was higher at the left wrist than at the right. The vessels were not hardened to palpation. Pulsation could not be detected either in the abdominal aorta or in the great vessels of the lower limbs. Palpation showed the apex beat to be in the fifth left interspace, four inches from the mid-line. There was marked pulsation of both carotids, and also of the aorta in the episternal notch, but no tracheal tugging. Percussion did not elicit any obvious change in cardiac dulness. On auscultation at the apex three heart sounds were heard, the third following at a short interval after an apparent second sound. One inch internal to the apex beat systolic and diastolic murmurs were present, the heart sounds themselves being well heard and of good tone. At this point the third sound was not audible and the diastolic murmur partly obscured and followed the second sound. There was nothing to suggest the presence of a presystolic murmur. At the aortic cartilage and down the sternum to the xiphoid there was a systolic murmur, but the second sound was pure. Over the aorta and great vessels a systolic bruit was heard, and also in both interscapular areas, especially at the third and fourth left interspaces. In the second left interspace in front, about one and a half inches from the mid-line, a continuous machinery murmur of the water-wheel type was heard, being crescendo during systole and continuing throughout diastole. This murmur was also conducted up to the left clavicle. Throughout the period of observation there were considerable variations in the systolic blood pressure from day to day, but at first there was a constant difference of some 50 millimetres of mercury between the readings obtained in the two arms, the left being the higher. The readings in both upper limbs were greatly in excess of those in the legs, typical figures being: right arm, 175/90; left arm, 225/110; legs, 130 systolic. 
On admission the urine showed a trace of albumin and contained a few polymorphs and coliform organisms. No casts were found. A urea concentration test gave a figure of 2.65 per cent at the second hour. The blood urea was $39 \mathrm{mg}$. per 100 c.c. Later the urine became normal. A gynæcological examination did not reveal any abnormality.

Blood examination: Hæmoglobin 82 per cent, red blood cells 4,700,000 per c.mm., white blood cells 11,200 per c.mm. Examination of blood films, including a differential count, did not reveal any abnormality. The Kahn test was negative. The blood sedimentation rate was well within normal limits.

Ophthalmic examination: The pupils were always moderately dilated and unequal, the degree of inequality varying from day to day; sometimes the one and sometimes the other was the more dilated. The reactions both to light and to convergence were sluggish. The fundi showed no evidence of arterial or venous pulsation or any other abnormality.

Radiological examination of the chest showed enlargement of the right ventricle and a prominent and pulsatile conus; the aortic knuckle was somewhat small (Fig. 1). Fig. 2, a similar view from one of our uncomplicated

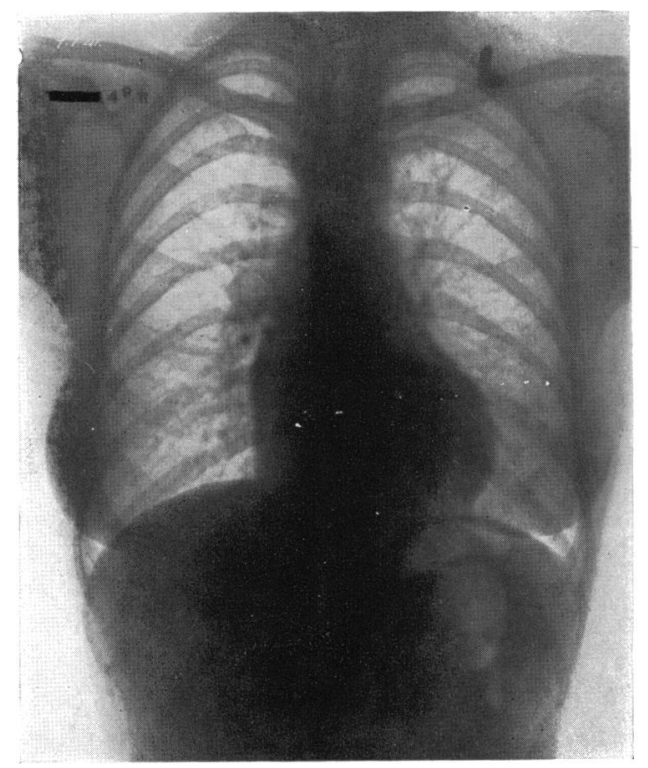

FIG. 1.-Antero-posterior view of our patient, at 2 metres, showing right-sided cardiac enlargement, and erosion of ribs.

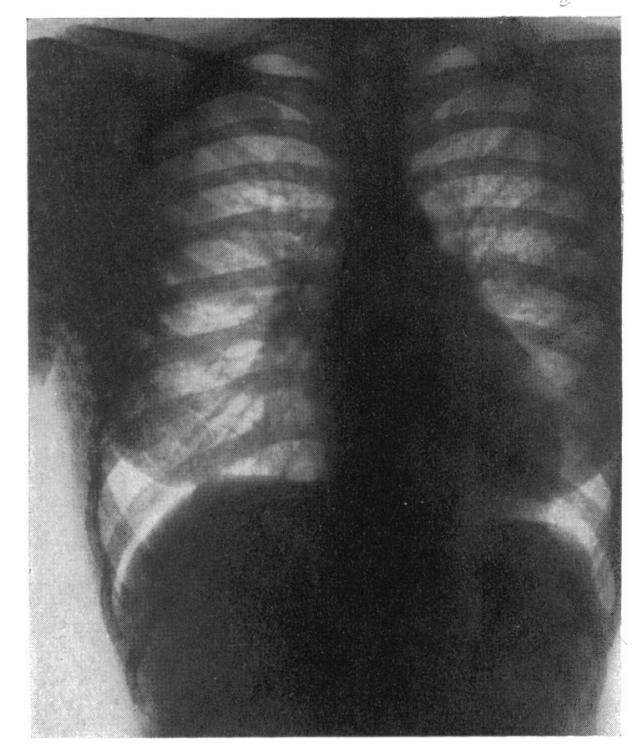

FIG. 2.-Antero-posterior view, at 2 metres, of an uncomplicated case of patent ductus arteriosus.

cases of patent ductus arteriosus, a female aged 28 years, is included for comparison. Although oblique views of the subject of this paper revealed an apparently normal ascending and transverse aorta, the remainder of the arch could not be visualized. In the left (II) oblique position the aorta and its branches, as Lewis (1931) has described, seemed to rise as a column from the heart shadow up into the root of the neck. 
Rösler's sign-erosion of ribs-was present. This is clearly seen in Figs. 1, an antero-posterior view taken at two metres, and in greater detail in Fig. 3. In

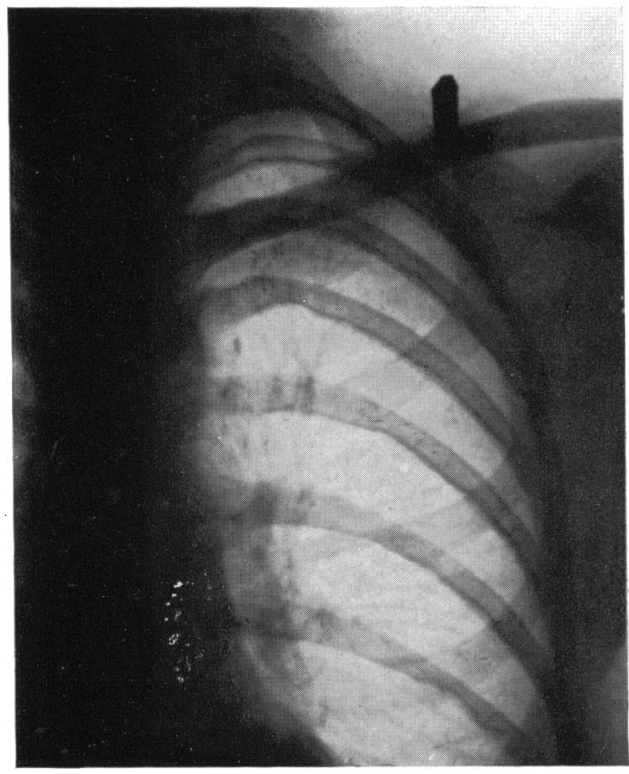

FIG. 3.-Left upper quadrant, showing erosion of ribs in detail.

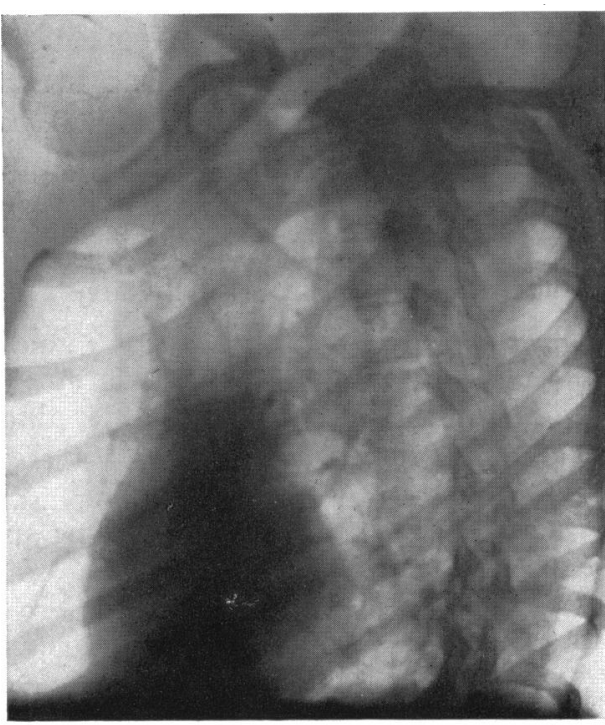

FIG. 4.-Left (II) oblique view of our patient.

Fig. 4, a left (II) oblique view, the prominent pulmonary conus is well seen, but the descending arch of the aorta is not visualized.

An electrocardiogram, Fig. 5, shows changes in the ventricular complexes comparable with those described by Evans and Turnbull (1937), following the work of Wilson et al. (1934), as denoting right bundle branch block. This newer curve, which is said to be much commoner than the one standard for right bundle branch block, is characterized by a deep $\mathrm{S}$ wave as a component of a wide QRS complex in lead I (measuring 0.12 sec. in this case), and also in lead II, by the QRS complex in lead III being directed downwards ; and by the T wave being upright in leads I and II and inverted in lead III. The changes seen in the sternal lead (Fig. 5) would seem to be in conformity with this diagnosis.

After three weeks' rest in bed the patient stated that she felt fitter in all respects. She had been afebrile throughout this period. The difference between the two radial pulses and the two brachial blood pressures became much less marked. The systolic pressure in the arms, however, remained considerably in excess of that in the legs, typical findings being : right arm, 205/120; left arm, 215/120; legs, 130 systolic.

\section{Discussion}

This case presents many unusual features, both in the history and clinical findings. There had been no evidence of cardiac insufficiency until the patient's twentieth year, when she was a seven months primagravida. At that time the 

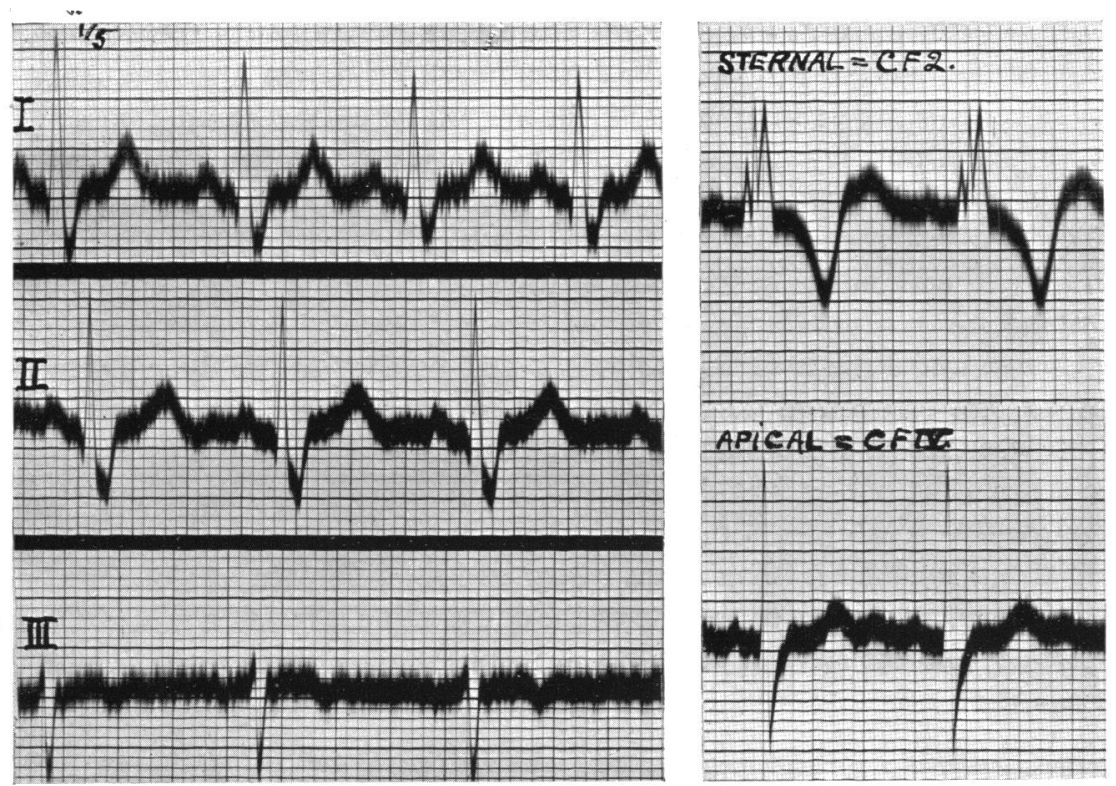

FIG. 5.-Electrocardiogram of the case described, showing a conduction defect comparable with the "newer" type of right bundle branch block.

development of headache, nausea, and vomiting, combined with the presence of albuminuria, were interpreted as being due to renal disease. In view of her subsequent history and the results of the present investigation (which inter alia show no evidence of impaired renal function but only of a mild urinary infection that responded to the simplest therapeutic measures) it seems reasonable to suggest an alternative explanation. Her symptoms may be interpreted as due to the development of chronic venous congestion through the late months of pregnancy overtaxing a circulation already hampered by a congenital cardiac defect. It is now suggested that consideration of the physical findings indicates a complex defect of which the several components are outlined.

(1) Coarctation of the Aorta. X-ray films taken at two metres showed an ascending aorta of normal size, with a rather undersized knuckle, while the remainder of the arch was not visualized. Moreover, Rösler's sign was present. In addition a loud systolic bruit was heard at the aortic cartilage and was conducted into the neck and to the interscapular area posteriorly. The blood pressure in either arm was markedly raised, and in great excess of that in the lower limbs. The gross difference in pressure between the two upper limbs noted on admission to hospital, presumably with a reduced cardiac reserve, when the left brachial exceeded the right by some 50 millimetres of mercury, is explainable by the coarctation being situated just distal to the entry of the patent ductus to the aorta, from which the great vessels may take an unusual origin.

(2) Patency of the Ductus Arteriosus, as instanced by the characteristic machinery murmur heard in the second left space and conducted up to the left clavicle. In this case the shunt was predominantly arterio-venous, the patient being free from cyanosis. 
(3) A Ventricular Septal Defect is postulated on account of the well-marked and separate systolic and diastolic bruits heard inside the apex beat, and the bizarre cardiogram comparable with the Wilson type, now recognized as indicative of right bundle branch block. Radiological evidence indicated enlargement of the right ventricle and of the conus. In Abbott's analysed series of 110 cases of pulmonary stenosis there was a septal defect in 101. On the other hand, in 70 with aortic coarctation of the so-called adult type there were only 7 instances.

Cowan and Ritchie (1935) point out that patency of the ductus arteriosus may be first recognized during an illness, or in later life on examination for military service or life assurance. We have noted 4 cases of this anomaly in one year in the out-patient department of a military hospital. Similarly, it is of interest to recall that 8 of Lewis's 9 patients with coarctation of the aorta were army pensioners. Evans has recognized six different types of coarctation of the aorta, according to the site of the constriction, the patency of the ductus arteriosus, and the state of the aorta proximal to the constriction. Under this classification our case would be placed in Type I. Among the 8 cases of this type that he described, only one had reached adult life, a man aged thirty years, in whom necropsy showed wide patency of the ductus with enlargement of the right heart. Where the coarctation occurs at its usual site-distal to the origin of the left subclavian-the radial pulses are equal. Various observers, including King (1937), Parker and Dry (1938), and Bayley and Holoubek (1940), have noted that the pulses may be unequal, the right being more forceful than the left, and have explained this by a coarctation at or above the origin of the left subclavian artery. In our case, however, the left pulse was more forceful than the right. In the limited review of the reported cases that we have been able to attempt under present conditions we have only noted two similar cases (King, 1926, and East, 1932). It is realized that the explanation of the physical findings which we have advanced is a purely hypothetical one, and that the final truth can only be revealed at necropsy.

Our grateful thanks are due to Dr. G. A. Allan for his criticism, and to Colonel D. F. Mackenzie, D.S.O., late R.A.M.C., and Colonel R. A. Lennie, T.D., late R.A.M.C., for permission to publish this case.

We have pleasure in acknowledging our indebtedness to Major W. C. Armstrong, R.A.M.C., Major E. G. Recordon, R.A.M.C., and Lieut. D. H. Cummack, R.A.M.C., for the gynæcological, ophthalmic, and radiological examinations, and to Mr. R. P. Danskin, of Edinburgh Royal Infirmary, who took the electrocardiogram.

\section{REFERENCES}

Abbott, M. E. (1936). Atlas of Congenital Cardiac Disease, New York.

Bayley, R. H., and Holoubek, J. E. (1940). Brit. Heart J., 2, 208.

Blackford, L. M. (1928). Arch. intern. Med., 41, 702.

Cowan, J., and Ritchie, W. T. (1935). Diseases of the Heart, London, p. 479.

East, T. (1932). Proc. Roy. Soc. Med., 25, 797.

Evans, W. (1933). Quart. J. Med., N.S., 2, 1.

- and Turnbull, H. M. (1937). Lancet, $2,1127$.

King, J. T. (1926). Arch. intern. Med., 38, 69.

(1937). Ann. intern. Med., 10, 1802.

Lewis, T. (1931-3). Heart, 16, 205.

Parker, R. L., and Dry, T. J. (1938). Amer. Heart J., 15, 739.

Wilson, F. N., Johnston, F. D., Hill, I. G. W., MacLeod, A. G., and Barker, P. S. (1934). Ibid., 9, 459. 